\title{
EVALUATION OF PHYSICAL FITNESS IN CHILDREN WITH TYPE 1 DIABETES
}

\section{Aisha A Hagag ${ }^{1}$, Mohamed K Seyam², Naglaa A Zaky3, Eman Y Salem.}

${ }^{* 1}$ Department of Physical Therapy for Cardiovascular/Respiratory Disorders and Geriatrics, Faculty of Physical Therapy, Cairo University, Egypt.

${ }^{2}$ Departement of physical therapy, Zagazig University Hospital, Egypt.

${ }^{3}$ Department of Physical Therapy for Growth and Development Disorders in Children and its Surgery, Faculty of Physical Therapy, Cairo University, Egypt.

${ }^{4}$ Department of Fitness and Rehabilitation Unit, Cairo University Hospitals, Egypt.

\section{ABSTRACT}

Purpose: the aim of the study was to compare the physical fitness of children with type 1 diabetes with reference to healthy controls.

Subjects and Methods: thirty male children with type 1 diabetes have been selected randomly to participate in this study; their ages ranged from 12 to 17 years old. They were referred from out patient's clinic of Pediatrics in Zagazig university hospital. Thirty healthy children volunteers participated to represent the control group; they were matched in age to the diabetic group.

Procedure: Physical fitness was evaluated using the "EUROFIT Physical Fitness Test Battery". This battery estimates body composition, cardiopulmonary, and musculoskeletal fitness.

Results: there were no significant differences concerning BMI, skin folds and PBF between the diabetic and control groups. The 6-min walking distance and VO2max were significantly lower in the diabetic group (PB $\leq 0.05)$. Jump-stretch, handgrip and side-bending of trunk tests were also lower in the diabetic group.

Conclusion: physical functional capacity is much lower in diabetic children than in age-matched control subjects.

KEY WORDS: Type 1 diabetes, physical fitness, Eurofit test battery.

Address for correspondence: Dr. Aisha A Hagag, Department of Physical Therapy for Cardiovascular/Respiratory Disorders and Geriatrics, Faculty of Physical Therapy, Cairo University, Egypt. E-Mail: Aishahagag73@gmail.com

\section{Access this Article online}

\begin{tabular}{|c|c|c|}
\hline \multirow{2}{*}{$\begin{array}{l}\text { Quick Response code } \\
\text { 口is }\end{array}$} & \multicolumn{2}{|c|}{$\begin{array}{l}\text { International Journal of Physiotherapy and Research } \\
\text { ISSN 2321- } 1822 \\
\text { www.ijmhr.org/ijpr.html }\end{array}$} \\
\hline & $\begin{array}{l}\text { Received: 18-07-2017 } \\
\text { Peer Review: 19-07-2017 } \\
\text { Revised: None }\end{array}$ & $\begin{array}{l}\text { Accepted: 16-08-2017 } \\
\text { Published (O): 11-09-2017 } \\
\text { Published (P): 11-10-2017 }\end{array}$ \\
\hline
\end{tabular}

\section{INTRODUCTION}

Diabetes mellitus type 1 (T1D) is a multifactorial autoimmune disease characterized by complete destruction of pancreatic beta cells and loss of insulin production, caused by multiple genetic and environmental influences [1].

A number of antibodies are detected in persons with T1D which are believed to cause a specific loss of pancreatic beta cells [2]. They are known as the insulin-producing cells of the body, when their numbers have decreased below a threshold level, the ability of the body to regulate blood glucose levels, and diabetes results. Despite T1D comprises only a small percentage (5-15\%) of the total cases of diabetes, it is found that around the world, about 33 million people have 
this disease [3].

Besides, the incidence of T1D is increasing by 3-5\% per year, may be attributed to unidentified environmental factors [4-5]. Physical fitness is defined as the ability to perform daily activities willingly and actively. The World Health Organization (WHO) describes the term as social, mental and physical well-being. Physical fitness consists of components of sports as well as those of health. Health related physical fitness involves cardiopulmonary fitness, muscle endurance, strength, flexibility and body composition [6].

Different field test batteries on physical fitness have been developed that assess different physical fitness parameters [7]. One of these tests is the Eurofit test battery [8].

The Eurofit test battery is designed by the Committee for the Development of Sport of the Council of Europe to evaluate health related fitness of individuals, communities and population samples [8].

The EUROFIT Test Battery is composed of simple and relatively inexpensive tests which can be administered by health team members either as part of or in addition to the regular school physical education program. It can also be used in sports clubs or in sports medical centers [9].

Children's fitness requires special emphasis in order to design the appropriate physical therapy program in the best way possible and also to attempt to modify more fundamentally the physical activity component of the lifestyle of the child with type 1 diabetes. To achieve this, a strong need to change attitudes in society and to alert those responsible for the education, condition and life style of children. Hard facts concerning the levels of fitness in children are essential to such action. These facts are not available. Very few measures have been made in most countries of the fitness of children, and usually those measures have been made on selected groups [9].

The aim of this study was to evaluate physical fitness in children with type 1 diabetes by use of the EUROFIT test battery and also to see how effective this battery may be in the evaluation of diabetic children. This is expected to constitute the basis for the preparation of individual exercise programs.

\section{METHODOLOGY}

Subjects: Thirty male children with type 1 diabetes were recruited from out patient's clinic of Pediatrics in Zagazig university hospital. Thirty aged-matched healthy volunteers serve as a control group. The study had local research and ethics committee approval and all subjects, parents gave written consent.

Inclusive criteria: All subjects were ambulant without assistance and with history of type 1 diabetes, HbA1c was between 7 and 10, The age of participants ranged from 12 to 17 years old, Duration of diabetes not less than 5 years, Subjects did not participate in regular exercise/ diet programs for the preceding 6 months.

Exclusion criteria: Subjects with a history or clinical evidence of orthopedic, neurological or cardiopulmonary disorders were excluded.

Procedure and measures: The closest hemoglobin $\mathrm{A} 1 \mathrm{c}(\mathrm{HbA} 1 \mathrm{c})$ obtained in the routine care was used to assess long-term metabolic control of the patients.

The physical fitness of the patients, including body composition, cardiopulmonary fitness, motor and musculoskeletal system fitness was evaluated using the EUROFIT Test Battery.

In order to assess body composition, height, body weight, body mass index (BMI), skin fold thickness, and percentage of body fat (PBF) were measured. Body mass index was calculated as body weight in $\mathrm{kg}$ divided by the square of height in meters $\left(\mathrm{kg} / \mathrm{m}^{2}\right)$.

For the skin fold thickness measurements, Calipers with $0.2 \mathrm{~mm}$ spaces were used and the measurements have been applied on the right side of the body. Measurement sites used were triceps and calf skin folds Calculation of the PBF using the sum of the folds using specific equation. Equation to estimate percent body fat of children and youths from the sum of triceps and calf skin folds is as \% body fat $=(0.735 *$ sum of skin folds)+1.0 [10].

The 6-min walking test was used to determine cardiopulmonary fitness, at the end of the test the distance walked was recorded. A special formula: Mean Peak VO2 $(\mathrm{ml} / \mathrm{kg} / \mathrm{min})=4.948+$ $0.023 *$ Mean 6 MWD (meters)was used to 
determine $\operatorname{VO} 2 \mathrm{max}(\mathrm{ml} / \mathrm{kg} / \mathrm{min}) \cdot[11]$.

To evaluate musculoskeletal fitness, the vertical jump test, the grip strength test, and sidebendingof the trunk were used.

The vertical jump test was used in order to measure lower extremity muscle strength. The subject jumped as high as possible at a $20-\mathrm{cm}$ distance from the wall and the distance jumped was measured.

Grip strength was measured with dynamometer once with each elbow in flexion and once with each elbow in extension. Each measurement was repeated twice and the higher score was recorded.

For the side-bending tests, the patients stood upright against a wall on two parallel lines at right angles to the wall and $15 \mathrm{~cm}$ apart. The patients held their arms straight against the sides of their body. The position of the middle finger on eachside was marked with a horizontal line on the lateral thigh. The subject was then asked to bend sideways as far as possible while maintaining contact between the back and the wall. The distance between the first and last position of the middle finger was recorded.

The Flamingo balance test used to measure static balance. To administer the flamingo test, the subject was asked to stand on the wooden beam ( $50 \mathrm{~cm}$ long, $5 \mathrm{~cm}$ high, $3 \mathrm{~cm}$ wide) with shoes removed on the tested leg and bend the free leg at the knee, and the foot of this leg was held close to the buttocks with both hands on the iliac crests, standing like a Flamingo. Participants were instructed to maintain this position as long as they can. Stopwatch was used to note each time the person loses balance either by falling off the beam or letting go of the foot being held or hands removed off the body. Tests were practiced with eyes open without shoes for both the right and left leg [12].

\section{Statistics:}

Descriptive characteristics (mean and SD) were performed for all parameters. Analysis was performed with SPSS 19.0. Parametric analysis using the independent-sample T-test was used to determine the significance of the outcome measurements between the two groups. Comparisons were considered significant at a $P$ value of 0.05 or less.

\section{RESULTS}

General Characteristics of both groups: There were no significant differences between groups in age, weight and height (Table 1).

Table 1: Subjects characteristics.

\begin{tabular}{|c|c|c|c|c|c|c|c|c|c|}
\hline \multirow{3}{*}{ Item } & \multicolumn{3}{|c|}{ Diabetic boys $(n=30)$} & \multicolumn{3}{|c|}{ Control boys $(n=30)$} & \multirow{3}{*}{$t$-value } & \multirow{3}{*}{$p$-value } & \multirow{3}{*}{ Sig } \\
\hline & \multirow{2}{*}{$X \pm S D$} & \multicolumn{2}{|c|}{ Range } & \multirow{2}{*}{$X \pm S D$} & \multicolumn{2}{|c|}{ Range } & & & \\
\hline & & Min & Max & & Min & Max & & & \\
\hline $\begin{array}{l}\text { Age } \\
\text { (years) }\end{array}$ & $14 \pm 1.3$ & 12 & 17 & $14.3 \pm 1.1$ & 12 & 16 & 0.62 & 0.5 & NS \\
\hline $\begin{array}{l}\text { Weight } \\
(\mathrm{kg})\end{array}$ & $50.67 \pm 7.9$ & 44 & 60 & $53.9 \pm 7.3$ & 47 & 60 & 1.63 & 0.2 & NS \\
\hline $\begin{array}{l}\text { Height } \\
(\mathrm{cm})\end{array}$ & $145.2 \pm 4.5$ & 133 & 160 & $147.8 \pm 5.9$ & 135 & 163 & 1.12 & 0.24 & NS \\
\hline
\end{tabular}

Values: mean $\pm S D$

Comparison of the body composition values: There were no significant differences concerning body mass index (BMI), percent of body fat (PBF), triceps and calf skin fold thickness between diabetic and control groups (Table 2).

Table 2: Body composition values of boys with type 1 diabetes compared to healthy control groups.

\begin{tabular}{|c|c|c|c|c|}
\hline Item & \begin{tabular}{|c|} 
Diabetic boys \\
$(n=30)$
\end{tabular} & \begin{tabular}{|c|}
$\begin{array}{c}\text { Control boys } \\
(n=30)\end{array}$ \\
\end{tabular} & $p$-value & Sig \\
\hline $\mathrm{BMI}\left(\mathrm{Kg} / \mathrm{m}^{2}\right)$ & $20.2 \pm 2$ & $22.3 \pm$ & 0.07 & NS \\
\hline PBF\% & $17 \pm 4$ & $20 \pm 3$ & 0.21 & $\overline{N S}$ \\
\hline $\begin{array}{c}\text { Triceps skin fold } \\
\text { (mm) }\end{array}$ & $25 \pm 3.3$ & $29 \pm 2.1$ & 0.32 & NS \\
\hline $\begin{array}{l}\text { Calf skin fold } \\
(\mathrm{mm})\end{array}$ & $29 \pm 2.5$ & $31 \pm 1.3$ & 0.12 & NS \\
\hline
\end{tabular}

Values: mean $\pm S D$, BMI:body mass index , PBF:percent of body fat Comparison of physical fitness: There were statistical significant differences concerning the eurofit physical fitness test results between the diabetic and control groups (Table 3).

Table 3: Eurofit test results of boys with type 1 diabetes compared to healthy control groups.

\begin{tabular}{|c|c|c|c|}
\hline Item & $\begin{array}{c}\text { Diabetic boys } \\
(\mathbf{N}=30)\end{array}$ & $\begin{array}{c}\text { Control boys } \\
(\mathbf{N}=30)\end{array}$ & -value \\
\hline Distance walked (m) & $230 \pm 33$ & $300 \pm 45$ & $.000^{*}$ \\
\hline VO2max (ml /kg/min) & $32 \pm 5.2$ & $45 \pm 7.4$ & $.001^{*}$ \\
\hline Vertical jump test (cm) & $15 \pm 1.2$ & $25 \pm 2.4$ & $.013^{*}$ \\
\hline Hand grip & & & \\
*With elbow flexion & $18 \pm 2.3$ & $27 \pm 2.1$ & $.015^{*}$ \\
*With elbow extension & $19 \pm 1.1$ & $25 \pm 3.2$ & $.002^{*}$ \\
\hline (R) Side-bending test (cm) & $14 \pm 1.1$ & $19 \pm 1.9$ & $.000^{*}$ \\
\hline (L) side bending test (cm) & $13 \pm 2.3$ & $17 \pm 1.2$ & $.011^{*}$ \\
\hline $\begin{array}{c}\text { Flamingo balance; } \\
\text { (No of errors)** }\end{array}$ & $9.19 \pm 7.57$ & $5.27 \pm 5.52$ & $.003^{*}$ \\
\hline
\end{tabular}

Values: mean $\pm S D, \mathrm{R}$ : right, $\mathrm{L}$ :left, $*$ :Sig $(\mathrm{P} \leq .05),{ }^{*}$ Numbers of steps down from the beam losing the balance.

\section{DISCUSSION}

In the present study, we investigated the muscloskeletal and cardiorespiratory fitness of male children and adolescents with type 1 diabetes using the standardized Eurofit test 
battery and compared the results with age matched control groups. Boys with type 1 diabetes showed poorer physical fitness levels in several tests than their non-diabetic peers.

Previous studies assessed the physical fitness in children with type 1 diabetes. These studies investigated the cardiorespiratory fitness comparing results with non-diabetic children. All investigations observed reduced cardiorespiratory performance in children and adolescents with diabetes $[13,14]$.

However, this is the first study, in which parallel assessments of Muscloskeletal, body composition and cardiorespiratory function were carried out in male children with type 1 diabetes using the Eurofit test battery. These tests are standardized and widely used methods of estimating the physical fitness of children and adolescents

The reason why children and adolescents with diabetes showed impaired musckloskeletal and cardiovascular on various tests is not clear. It has been suggested that lower physical activity or physiological changes resulting from the pathology of diabetes itself could result in reduced fitness in children with diabetes [13].

It is suggested that children with diabetes, because of the fear of hypoglycemia as a consequence of exercise, participate less intensively [14]. In sport activities, have less daily physical activity, and may have less skill to perform such tests than non-diabetic peers [15].

Further possibilities are that early complications of diabetes as diabetic myopathy may contribute to reduced physical fitness achievements. Cardiovascular autonomic dysfunction also interfered with testing results [16].

Microangiopathic vascular lesions and peripheral neuropathy may lead to disturbed muscle innervations and an impairment of motor performance [17].

In the present study we evaluated the maximum aerobic capacity by using 6 min walking test which agreed with the study ${ }^{(11)}$ that concluded that 6MWT is of moderate-to-vigorous intensity, and may be useful in the classification of aerobic fitness, which is associated with health outcomes. Inclusion of further patient characteristics greatly increases the predictive value of the
6MWT for estimating VO2 max, which has important implications for those seeking a noninvasive and simple-to-use determinant of maximal aerobic power.

This is also in agreement with the study [18] which concluded that the distance ambulated during a 6'WT can predict VO2 max in patients with end-stage lung disease. The addition of several patient characteristics can increase the ability to predict VO2 max and account for more of the variability. Such information is valuable when assessing patient response to therapeutic intervention if respiratory gas analysis is unavailable or impractical.

In our study there was lower VO2 max in diabetic youth than healthy peers which suggest the importance of the use of aerobic exercises in the treatment and care of type 1 diabetes.

Peripheral neuropathy and axonal loss in diabetic patients cause atrophy and reduced muscle strength, especially in ankle dorsi-flexion and plantar-flexion, knee flexion and extension [19].

Andersan et al.[20] evaluated muscle strength in tibialis anterior and quadriceps femoris of 34 Type 2 and 19 Type 1 diabetic patients using the isokinetic dynamometer. They reported that there was a significant reduction in muscle strength of tibialis anterior and quadriceps femoris and attributed this to axonal loss. In another study in which wrist extension and flexion strength were evaluated in addition to lower extremity strength, values were reported to be lower in 56 individuals with Type 1 diabetes with duration over 20 years [21].

In our study, the results of the vertical jump test were relatively lower in the diabetic youth. Henten et al. [22]. assessed the muscle strength of 553 male and 629 female subjects using the JAMAR dynometer and suggested that male patients have higher values than females. On comparing handgrip test results we found that the diabetic youth had lower values than control subjects.

Flexibility is an important component of physical fitness. Our diabetic subjects had lower test values than healthy peers for the sidebending test, suggesting that flexibility in these patients is also impaired

In conclusion, both musculoskeletal and cardio- 
respiratory fitness are impaired in youths with type 1 diabetes. Regular and parallel assessments of motor and cardiorespiratory functions by the Eurofit battery tests may help to identify the individual needs of special exercise activities that contribute to better physical condition and metabolic control of children and adolescents with type 1 diabetes. However, further studies are necessary to explain the mechanisms by which diabetes leads to reduced fitness and to examine the effect of lifestyle intervention on the feasibility of improving cardiovascular fitness.

\section{ACKNOWLEDGEMENTS}

We are very grateful to all diabetic children and the control schoolboys for taking part in this research study. We would like to thank the physicians and assistants of the outpatient clinic of Pediatrics at zagazig university hospital.

\section{Conflicts of interest: None}

\section{REFERENCES}

[1]. Atkinson M. A. and Maclaren N. K. Mechanisms of disease: the pathogenesis of insulin-dependent diabetes mellitus. The New England Journal of Medicine 1994;331(21):1428-1436.

[2]. Mathis D., Vence L., and Benoist C. â-cell death during progression to diabetes. Nature 2001; 414(6865):792-798.

[3]. Komatsu W. R., Lima Gabbay M. A., Castro M. L. et al. Aerobic exercise capacity in normal adolescents and those with type 1 diabetes mellitus," Pediatric Diabetes 2005;6(3):145-149.

[4]. Williams B. K., Guelfi K. J., Jones T. W., and Davis E.A. Lower cardiorespiratory fitness in children with type 1 diabetes. Diabetic Medicine 2011;28(8):10051007.

[5]. Haugstvedt A., Wentzel-Larsen T., Rokne B., and Graue M. Psychosocial family factors and glycemic control among children aged 1-15 years with type 1 diabetes: a population-based survey. BMC Pediatrics 2011;11:118.

[6]. Winnick JP, Short FX. The Brockport Physical Fitness Test Manual. Champaign, IL: Human Kinetics, 1999.

[7]. Vanhees L, Lefevre J, Philippaerts R, Martensa M, Huygens $W$, Troosters $T$, et al. How to assess physical activity? How to assess physical fitness? Eur J Cardiovasc Prev Rehabil 2005;12:102-14.

[8]. Oja P, and Tuxworth B. Eurofit for adults. Assessment of health-related fitness. Strasbourg: Council of Europe-UKK Institute, Tampere; 1995.

[9]. TESTING PHYSICAL FITNESS EUROFIT Experimental Battery PROVISIONAL HANDBOOK. Republished on the Internet by www.bitworks-engineering.co.uk. March 2011.
[10]. Dezenberg CV, Nagy TR, Gower BA, Johnson R, Goran MI.Predicting body composition from anthropometry in preadolescent children. Int J Obesity 1999;23:253-259.

[11]. Robert M Ross, Jayasimha N Murthy, Istvan D Wollak and Andrew S Jackson: The six minute walk test accurately estimates mean peak oxygen uptake BMC Pulmonary Medicine, 2010;10:31.

[12]. Committee of Experts on Sports Research. Eurofit: Handbook for the Eurofit tests of physical fitness, $2^{\text {nd }}$ edn. Strasbourg: Council of Europe, Committee for the Development of Sports, 2003.

[13]. Williams BK, Guelfi KJ, Jones TW, Davis EA. Lower cardiorespiratory fitness in childrenwith type 1 diabetes. Diabet Med. 2011;28:1005-1007.

[14]. Maggio AB, Hofer MF, Martin XE, Marchand LM, Beghetti M, Farpour-Lambert NJ. Reduced physical activity level and cardiorespiratory fitness in children with chronic diseases. Eur J Pediatr. 2010;169:1187-1193.

[15]. Luk'acs A,Mayer K, Juh'asz E, Varga B, Fodor B, Barkai L. Reduced physical fitness in children and adolescents with type 1 diabetes. Pediatric Diabetes 2012;13:432-437.

[16]. Barkai L, Peja M, V'amosi I. Physical work capacity in diabetic children and adolescents with and without cardiovascular autonomic ysfunction. Diabet Med 1996;13:254-258.

[17]. Krause MP, Riddell MC, Hawke TJ. Effects of type 1 diabetes mellitus on skeletal muscle: clinical observations and physiological mechanisms. Pediatr Diabetes 2011;12:345-364.

[18]. Cahalin L, Pappagianopoulos P, Prevost S, Wain J, Ginns L; The relationship of the 6-min walk test to maximal oxygen consumption in transplant candidates with end-stage lung disease.Chest. 1995 Aug;108(2):452-9.

[19]. H. Andersen, Motor function in diabetic neuropathy, Acta Neurol. Scand. 1999;100:211-220.

[20]. H. Andersen, E. Stalberg, M.D. Gjersta, Association of muscle strength and electrophysiological measures of reinnervation in diabetic neuropathy, Muscle Nerve 1998;21:1647-1654.

[21]. Mehtap O" zdirenc, Sevinc, Biberogclu b, Ays, e O. zcan a Evaluation of physical fitness in patients with Type 2 diabetes mellitus Diabetes Research and Clinical Practice 2003;60:171-176.

[22]. W.P. Hanten, W.Y. Chan, A.A. Austin, Maximum grip strength in normal subjects from 20_/64 years of age, J. Hand Ther. 1999;12:193-200.

How to cite this article: Aisha A Hagag, Mohamed K Seyam, Naglaa A Zaky'. Eman Y Salem. EVALUATION OF PHYSICAL FITNESS IN CHILDREN WITH TYPE 1 DIABETES. Int J Physiother Res 2017;5(5):2332-2336. DOI: 10.16965/ijpr.2017.202 